\title{
Análise da relação entre os indicadores de homicídios e a chegada de turistas estrangeiros no Brasil
}

\section{Arthur Caldeira Sanches}

Universidade Federal de Mato Grosso do Sul, Campo Grande, MS, Brasil

\section{Dyego de Oliveira Arruda}

Centro Federal de Educação Tecnológica Celso Suckow da Fonseca, Valença, RJ, Brasil

\section{Milton Augusto Pasquotto Mariani}

Universidade Federal de Mato Grosso do Sul, Campo Grande, MS, Brasil

O presente estudo tem como objetivo analisar as relações entre os indicadores de homicídio e a chegada de turistas estrangeiros no Brasil. Para tanto, realizou-se uma pesquisa quantitativa e descritiva, em que foram elaborados modelos de regressão linear. Os resultados do artigo sugerem evidências de que a chegada de turistas estrangeiros pode implicar o aumento do número absoluto de homicídios nas localidades turísticas. Ademais, constatou-se que um aumento da taxa de homicídios em um determinado ano faz com que ocorra uma queda, em parte, no número absoluto de visitantes estrangeiros no ano subsequente.

Palavras-chave: violência, homicídios, turismo, políticas públicas, regressão linear
Analysis of the Relationship between Homicide Indicators and the Arrival of Foreign Tourists in Brazil aims to analyze the relationship between homicide indicators and the arrival of foreign tourists in Brazil. A quantitative and descriptive research was carried out, in which linear regression models were created. The results show that the arrival of foreign tourists might cause an increase in the absolute number of homicides in tourist locations. In addition, we also found that an increase in the homicide rate in a given year caused a drop in the absolute number of foreign visitors in the subsequent year.

Keywords: violence, homicides, tourism, public policy, linear regression

\section{Introdução}

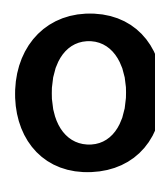

turismo representa uma atividade socioeconômica associada ao setor de prestação de serviços, com significativo potencial para a geração de receita e emprego nos locais em que é empreendido. Segundo dados do World Travel \& Tourism Council (2020a), as atividades direta ou indiretamente ligadas a ele foram responsáveis, em 2019, por mais de 10,3\% de toda a riqueza e renda gerada no mundo - o que representa mais de US\$ 8,9 trilhões em termos monetários. Considerando a capacidade de o turismo ser a força motriz da geração de ocupações, vale ressaltar que em 2019 mais de 330 milhões de pessoas no mundo estavam empregadas em setores direta ou indiretamente ligados a ele, ou seja, a atividade turística foi responsável por um em cada dez postos de trabalho (WTTC, 2020a).

No Brasil, a importância do turismo, em termos socioeconômicos, também é significativa: em 2019, as atividades direta ou indiretamente ligadas ao setor geraram mais de R \$ 551 bilhões, o que representa quase $8 \%$ de toda a riqueza e renda gerada no país no período (WTTC, 2020b). 
Além disso, mais de 7,9\% de todos os empregos criados no país no mesmo ano estiveram de alguma forma ligados ao setor de turismo (WTTC, 2020b).

Ao se avaliar como o turismo é operacionalizado, deve-se ressaltar que tal atividade é marcadamente sistêmica e, desse modo, movimenta uma miríade de setores econômicos, como os segmentos de hotelaria, alimentação e transporte, além dos empreendimentos ligados à recreação e ao lazer (ARRUDA, MARIANI e CALEMAN, 2014). Além disso, sabe-se que os esforços de difusão dessa atividade requerem a mobilização de toda a configuração do espaço que irá recepcionar as práticas turísticas, o que significa que aspectos ligados a infraestrutura, mobilidade, qualidade de vida e segurança, além da questão cênica e paisagística dos territórios, são cruciais nas dinâmicas de organização da atividade do turismo (SEDERATI, SANTOS e PINTASSILGO, 2019).

Tomé (2013), ao refletir acerca das influências dos índices de violência no turismo, sugere que o medo, as taxas de homicídios e a sensação de impunidade que paira sobre um determinado território podem fazer com que os potenciais visitantes repensem o desejo de ir até o local. Ainda segundo o autor, os indicadores de violência modificam sensivelmente a imagem - ou seja, o conjunto de crenças e percepções prévias - que os turistas têm sobre um determinado território.

Neumayer (2004), por seu turno, sugere que há uma influência negativa nos processos de chegada de turistas, sobretudo aqueles vindos de outros países, caso um determinado território seja alvo de práticas de violação de direitos humanos, conflitos armados ou eventos violentos motivados por questões políticas. Ressalte-se que, no escopo do turismo internacional, quanto menores os indicadores de violência (como as taxas de homicídio, por exemplo) no país de origem do visitante, menor será também a tolerância em relação a um cenário de violência, medo e conflito no território que se considera visitar (FOURIE, ROSSELLÓ-NADAL e SANTANA-GALLEGO, 2020).

Ferreira e Harmse (2000), além de Tomé (2013), sugerem que as taxas de homicídios são importantes indicativos da realidade de violência de uma determinada localidade, em uma dinâmica em que os turistas, no geral, tentam cercar-se dessas informações para determinar se efetivamente desejam ou não empreender esforços para visitar certa localidade. Ainda no entender dos autores, quanto menores as taxas de homicídio, mais consolidadas serão as crenças de que o local em análise é seguro, o que ampliará o desejo das pessoas de conhecer esses territórios.

Porém, a presença de visitantes pode ocasionar potencial ampliação nos indicadores de homicídios nos territórios turísticos, principalmente em função da maior circulação de dinheiro e de pessoas em determinados espaços, sem que as forças de segurança das localidades receptoras sejam capazes de ordenar esses fluxos e, naturalmente, coibir as práticas de quaisquer formas de violência, contra residentes e turistas (BASSIL, SALEH e ANWAR, 2019). Vale ainda dizer que os turistas podem, mesmo que de modo não volitivo, estimular práticas de especulação imobiliária, 
gentrificação e ações terroristas nos territórios, aspectos que, conjuntamente, impactam a realidade dos indicadores de homicídio de destinos turísticos (DEVINE, 2017; ARAÑA e LEÓN, 2008).

Ressalte-se que o Brasil é contemporaneamente um país com uma realidade crônica e preocupante de violência, com indicadores alarmantes no que tange aos registros de homicídios no país. Segundo dados sistematizados pelo Fórum Brasileiro de Segurança Pública (FBSP, 2020) o Brasil apresentou, em 2018, uma marca de 27,8 mortes violentas para cada 100 mil habitantes — indicador 30 vezes maior que as taxas da Europa, por exemplo.

Considerando esse cenário de violência no país, temos um conjunto de problemáticas passíveis de investigação: qual a relação entre os indicadores de homicídio e a chegada de turistas estrangeiros no Brasil? É possível que os indicadores de homicídio impactem positiva ou negativamente a chegada de turistas internacionais no país? Reciprocamente, será que a presença de visitantes internacionais no Brasil contribui, de modo positivo ou não, para a configuração dos indicadores de mortes violentas no país?

Desse modo, com base nos problemas de pesquisa acima delineados, o presente artigo tem como objetivo analisar, em termos estatísticos, as relações entre os indicadores de homicídio e a chegada ao Brasil de turistas provenientes de outros países. De modo geral, entende-se que um esforço de lançar luz aos problemas de pesquisa e ao objetivo deste estudo é importante, sobretudo porque seus resultados e inferências podem trazer insights para o planejamento e a difusão das estratégias de fomento ao turismo e de combate à violência no Brasil, concretizadas não raro por intermédio de políticas públicas.

\section{Turismo e violência: de que modo tais fenômenos se interrelacionam?}

Sendo o turismo uma atividade socioeconômica complexa e sistêmica, pode-se depreender que os turistas, ao decidirem quais destinos turísticos pretendem visitar, sofrem influências de uma gama de fenômenos, dos quais se destacam: a) os preços de deslocamento, hotéis, restaurantes e atrativos turísticos; b) as recomendações feitas por outros turistas que já estiveram no destino pretendido; c) as crenças quanto à beleza cênica e paisagística do local; d) as características da infraestrutura; e e) as características sociodemográficas gerais, que incluem os indicadores de desigualdade socioeconômica e violência do território (BOAVIDA-PORTUGAL, FERREIRA e ROCHA, 2017).

Pizam (1999) lembra que um dos aspectos centrais na escolha de destinos turísticos é o padrão de segurança fornecido pela localidade, uma vez que os visitantes, em geral, esperam alguma forma de proteção contra eventuais atos de violência que possam ocorrer, seja contra o patrimônio seja contra sua própria integridade física e moral. 
Complementando o argumento supracitado, Piscitelli (2017) aponta que o padrão de violência dos destinos turísticos é especialmente sensível na tomada de decisão de turistas que viajam sozinhos/as. Ainda segundo a autora, essa é uma preocupação em particular de turistas mulheres que viajam desacompanhadas, uma vez que não são incomuns os casos em que mulheres são vítimas de assédio, opressão e até violência física quando sozinhas. Em suma, o machismo é um dos fatores que explicam a ocorrência reiterada de violência contra mulheres que viajam sozinhas (Ibid.). Quando essas turistas são negras, as manifestações de violência são ainda mais incisivas também em função do racismo que oprime e subalterniza os corpos negros (SILVA, 2010).

López (2018), em uma análise calcada na realidade de destinos turísticos mexicanos, aponta que o medo e a violência nessas localidades implicam um menor grau de interação entre os residentes locais e os visitantes, em um arranjo que acaba por deturpar as experiências em torno da hospitalidade no destino. A autora sugere ainda que a violência desordena a prática turística e ressignifica o próprio ordenamento do território, uma vez que os turistas, tomados pelo medo, tenderão a conhecer apenas os locais considerados mais seguros e constantemente vigiados pelas forças de segurança locais, negligenciando todo o repertório de localidades e experiências que poderiam compor a prática turística, caso houvesse maiores e melhores níveis de segurança.

Turistas podem ser acometidos pelas seguintes formas de violência e/ou de crimes (BÜSCHER e FLETCHER, 2017; GLENSOR e PEAK, 2004): a) contra o patrimônio - casos em que os visitantes se tornam alvo de assaltos e golpes, sobretudo em função da crença de que os turistas circulam com muitos bens valiosos e dinheiro em espécie; b) violência física - circunstâncias em que os turistas são agredidos, o que em uma situação extrema pode ocasionar a morte; e c) crimes contra a honra - situações em que os visitantes, não raro em função de pertencerem a uma cultura específica, são acometidos por formas de humilhação, preconceito e até xenofobia.

Em muitas circunstâncias, os turistas são alvos preferenciais da prática de violência por ignorarem precauções corriqueiras e padrões culturais da localidade. Além disso, são naturalmente mais vulneráveis por estarem em um local pouco conhecido, principalmente se fora de seu país de residência (GRINOLS, MUSTARD e STAHA, 2011).

Uma consequência natural da violência em localidades turísticas, segundo Tomé (2017), é a inibição do fluxo de visitantes. Ainda segundo o autor, mesmo que a violência nos destinos turísticos não seja efetivamente dirigida aos turistas, índices alarmantes de homicídios, assaltos e/ou tiroteios acabam afastando potenciais visitantes. Desse modo, uma imagem significativamente depreciativa associada a um destino faz com que o turista subvalorize seus aspectos positivos - como riqueza cultural e beleza paisagística (Ibid.).

Freitas e Gotardo (2018), ao investigarem as percepções de turistas em relação ao Rio de Janeiro em 2016, quando a cidade recepcionou os Jogos Olímpicos, descobriram que o medo e a 
violência comumente associados ao Rio de Janeiro deram à cidade uma imagem eminentemente negativa e depreciativa e inibiram as intenções de turistas estrangeiros em conhecer o Rio e o país, de uma maneira geral.

A taxa de homicídios dos territórios turísticos, por ser um indicador da violência em níveis mais extremados, representa um dos fatores que mais inibe o fluxo de potenciais visitantes, que temem ser vítimas da violência local (TOMÉ, 2013). Partindo dessa perspectiva, pode-se depreender que o exercício de coibir os homicídios nos territórios turísticos, além de ser uma estratégia para a melhoria da qualidade de vida da população local, também pode fomentar a atividade turística (NEUMAYER, 2004).

Vale salientar que, em função do hábito cada vez mais corriqueiro de compartilhar experiências turísticas na internet, sejam elas positivas ou negativas, a difusão de notícias depreciativas relacionadas aos índices de violência em destinos turísticos ganhou uma escala considerável (AMORIN et al., 2012). Nesse sentido, é evidente o alcance das notícias e informações relacionadas aos destinos turísticos, o que empodera o turista, que viaja com um repertório maior de dados e informações sobre o destino, e gera desafios para o planejamento e a difusão do setor (FREITAS e GOTARDO, 2018).

De todo modo, não é um expediente fácil lidar com a temática da violência contra turistas nos destinos turísticos. Pizam, Tarlow e Bloom (1997) salientam que os destinos normalmente não apresentam recursos financeiros e materiais para a difusão, a bom termo, de estratégias de combate à violência contra turistas. Além disso, os autores destacam que há uma dificuldade crônica em registrar os casos de violência contra turistas, sobretudo quando o visitante não é fluente na língua local. No Brasil, por exemplo, há apenas 12 delegacias especializadas no atendimento ao turista, concentradas principalmente nas capitais dos estados do Sudeste e Nordeste. Mesmo nelas o atendimento se mostra insuficiente para que o visitante se sinta plenamente seguro e confiante nas forças de segurança do país (COSTA et al., 2018).

A despeito da percepção de que uma das consequências imediatas da violência nos destinos turísticos é inibir a chegada de novos turistas, Devine (2017) ressalta que é necessário considerar, nos estudos acerca das interrelações entre violência e turismo, que os visitantes em muitas circunstâncias são, de forma direta ou indireta, vetores da manifestação de formas de violência nos territórios turísticos. Segundo a autora, a presença desordenada de turistas nos territórios pode provocar: a) conjunturas de especulação imobiliária, o que leva a processos violentos de expulsão de comunidades tradicionais de certas localidades; b) inflação nos preços de bens e serviços básicos, expediente que penaliza sobretudo os residentes locais; c) tentativas de "apagamento" de formas tradicionais de vida e de manifestações culturais nos territórios; e d) ampliação dos índices de 
violência física e até de homicídios nos territórios, em função dos já citados processos de especulação imobiliária, ou mesmo em decorrência da maior circulação de pessoas e de dinheiro.

Coutinho, Nóbrega e Fazito (2020) ressaltam que a atividade do turismo, ao se estruturar a partir de uma lógica eminentemente capitalista e neoliberal, resulta no acirramento das desigualdades locais e no desordenamento dos territórios, aspectos que, em última análise, acabam por estimular o medo, a exclusão (sobretudo socioeconômica) e a violência. Ainda de acordo com os autores, há um conjunto de atividades deletérias e eminentemente violentas - como a prostituição e o tráfico de drogas - que resultam do turismo. E os destinos turísticos muitas vezes não dispõem de capacidade de controlar essas externalidades negativas decorrentes das práticas turísticas.

Complementando esse argumento, Araña e León (2008) salientam que a presença de turistas pode estimular ações de terrorismo e violência física nas localidades, alimentando interesses políticos, religiosos, sociais e/ou econômicos de grupos específicos presentes nos territórios turísticos. Ademais, vale considerar que atos terroristas e violentos contra visitantes ganham considerável repercussão midiática, o que torna destinos turísticos alvos preferenciais de grupos terroristas (BASSIL, SALEH e ANWAR, 2019).

Desse modo, com base nos aspectos aqui discutidos, surge a seguinte questão: é possível desnudar, a partir de procedimentos metodológicos quantitativos, as interrelações entre indicadores de violência (como o número de homicídios) e a chegada de visitantes nos destinos turísticos? No tópico a seguir apresentam-se os procedimentos metodológicos que sustentaram o conjunto de reflexões com base na questão em tela.

\section{Delineamentos metodológicos do estudo}

Esta pesquisa caracterizou-se como descritiva, uma vez que teve como propósito fundamental o detalhamento, a partir de um viés quantitativo, da relação entre indicadores de homicídio e a chegada de turistas internacionais no Brasil. A pesquisa descritiva é aquela cujo propósito consiste em caracterizar um fenômeno (como a interrelação entre variáveis), não raro por intermédio do uso de dados secundários, em um esforço de pesquisa em que não há o interesse precípuo de intervir diretamente na realidade pesquisada ao longo do processo de coleta e análise dos dados (PRODANOV e FREITAS, 2013).

No que tange à abordagem da pesquisa, o presente estudo é quantitativo, uma vez que teve como escopo a correlação de dados estatísticos quantificáveis, com o propósito de desnudar as interrelações de causa e efeito subjacentes às variáveis (CRESWELL, 2010). Para isso, foi utilizada a técnica de regressão linear, que, em linhas gerais, busca mostrar evidências estatísticas da 
capacidade de predição de uma variável dependente com base em outra variável, esta última considerada independente - potencialmente explicativa, portanto, do comportamento da variável dependente do modelo de regressão linear.

As informações necessárias para a condução das análises deste artigo provêm de fontes de dados secundários, disponibilizados de forma pública e gratuita, cujas características fundamentais estão expressas no Quadro 1.

Quadro 1: Especificação das variáveis e fontes de dados para o estudo

\begin{tabular}{|c|c|c|c|}
\hline Nome da variável & Descrição & Intervalo de tempo & Fonte \\
\hline $\begin{array}{c}\text { Número absoluto } \\
\text { de homicídios }\end{array}$ & $\begin{array}{c}\text { Valores absolutos da quantidade } \\
\text { de homicídios efetivamente } \\
\text { catalogados no Brasil }\end{array}$ & $\begin{array}{c}\text { Período entre 2003 e } \\
2016 \text { (periodicidade } \\
\text { mensal) }\end{array}$ & $\begin{array}{c}\text { Atlas da Violência } \\
\text { (FBSP, 2018) }\end{array}$ \\
\hline $\begin{array}{c}\text { Chegada de } \\
\text { turistas } \\
\text { estrangeiros } \\
\text { termos absolutos, de turistas } \\
\text { estrangeiros, de diferentes } \\
\text { nacionalidades, que chegam ao } \\
\text { Brasil, seja por via terrestre, aérea } \\
\text { ou aquaviária }\end{array}$ & $\begin{array}{c}\text { Período entre 2003 e } \\
2016 \text { (periodicidade } \\
\text { mensal) }\end{array}$ & $\begin{array}{c}\text { Anuário Estatístico do } \\
\text { Ministério do Turismo } \\
\text { (MTUR, 2018) }\end{array}$ \\
\hline
\end{tabular}

Fonte: Elaborado pelos autores.

Deve-se registrar que a escolha do "recorte temporal" adotado no âmbito deste estudo (entre 2003 e 2016) se deveu à disponibilidade dos dados, ou seja, optou-se por abranger os anos em que as variáveis consideradas (números de homicídios e chegadas de turistas internacionais no Brasil) foram divulgadas, ambas, de modo regular e com periodicidade mensal. Ainda que existam dados mais recentes sobre homicídios no Brasil (relativos a 2017, 2018 e 2019), à época da redação da última versão deste artigo ainda não estavam plenamente publicizados os dados acerca das chegadas de turistas estrangeiros ao país.

Ao todo, foram sistematizadas 168 observações, com periodicidade mensal, relativas aos dados de homicídios e chegada de turistas estrangeiros no Brasil, no intervalo de tempo especificado no Quadro 1.

A análise dos dados foi feita em duas etapas, nas quais foram conduzidas regressões lineares simples, cujas características fundamentais estão descritas no Quadro 2.

Quadro 2: Etapas e características fundamentais do processo de análise de dados do artigo

\begin{tabular}{|c|c|c|c|}
\hline Etapa & $\begin{array}{c}\text { Técnica } \\
\text { utilizada }\end{array}$ & $\begin{array}{c}\text { Características da } \\
\text { técnica }\end{array}$ & Qual o propósito da técnica, no artigo? \\
\hline $1^{\text {a }}$ & $\begin{array}{c}\text { Regressão linear } \\
\text { simples I }\end{array}$ & $\begin{array}{c}\text { Mostra a influência de } \\
\text { uma variável }\end{array}$ & $\begin{array}{c}\text { Revelar a magnitude da possível influência da } \\
\text { chegada de turistas internacionais (variável } \\
\text { independente) no número de homicídios que } \\
\text { ocorrem no Brasil (variável dependente) }\end{array}$ \\
$2^{\text {a }}$ & $\begin{array}{c}\text { Regressão linear } \\
\text { independente na variável } \\
\text { simples II }\end{array}$ & $\begin{array}{c}\text { Mostrar a possível influência da taxa de variação } \\
\text { de homicídios (variável independente) na } \\
\text { chegada de turistas internacionais no país } \\
\text { (variável dependente) }\end{array}$ \\
\hline
\end{tabular}

Fonte: Elaborado pelos autores a partir dos conceitos de Hair et al. (2009). 
Vale ressaltar que a regressão linear parte de um modelo (no caso, linear, de primeiro grau) feito para mostrar quão bem se pode representar e determinar o tipo de relação entre duas variáveis (HAIR et al, 2009). Em suma, o modelo de regressão linear vale-se de uma reta, desenvolvida por meio do método dos mínimos quadrados (que perfaz uma técnica estatística para maximizar o ajuste do modelo de regressão elaborado), cuja expressão é a seguinte:

$$
\mathrm{Y}=\alpha \mathrm{X}+\beta
$$

Y representa a variável dependente que se deseja analisar, ou seja, aquela variável explicada a partir de outra; X representa a variável independente; $\alpha$, o coeficiente angular, que indica $o$ quanto cada unidade da variável independente influencia a variável dependente; e $\beta$, o coeficiente linear, ou seja, o valor de Y quando X for zero.

Como técnica de validação dos modelos estatísticos lineares, foram utilizados os p-valores, capazes de indicar o nível de significância da regressão proposta, ou seja, a probabilidade de que as interrelações entre os dados sejam, efetivamente, válidas e coerentes com o comportamento que se manifesta na realidade.

Por fim, ressalte-se que, por conta da grande amplitude do termo "violência", optou-se por analisar as taxas e valores associados aos casos de homicídio, crimes violentos que tendem a causar impacto expressivo na percepção do público.

\section{Afinal, quais as relações entre homicídios e chegada de turistas internacionais no Brasil?}

Antes da apresentação dos principais resultados das análises estatísticas conduzidas neste estudo, optamos por descrever o panorama geral da realidade de violência no Brasil e os números de chegada de turistas internacionais no país.

O Gráfico 1 mostra o comportamento do número absoluto de homicídios nos estados da federação com indicadores de violência alarmantes (nominalmente, os estados são: Rio de Janeiro, São Paulo, Bahia, Minas Gerais e Pernambuco). Vale pontuar que, no Brasil como um todo, o número de homicídios saltou de 49.816 em 2002, para significativos 62.517 casos em 2016 - uma ampliação de mais de $25 \%$ no período em análise. 
Gráfico 1: Evolução dos números absolutos de homicídios nos estados mais violentos

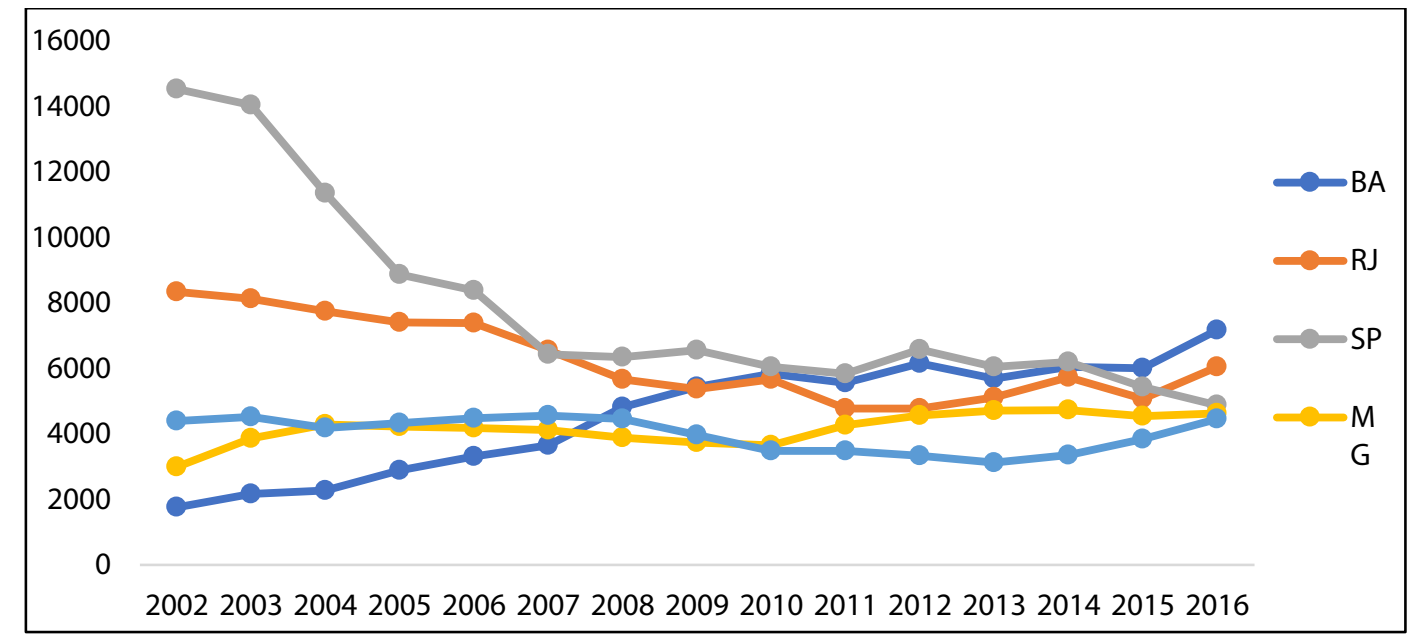

Fonte: Elaborado pelos autores com base em FBSP (2018).

Conforme é possível observar no Gráfico 1, em 2002 os estados com indicadores mais alarmantes de violência foram São Paulo e Rio de Janeiro. Não obstante, percebe-se que entre 2002 e 2016 ambos conseguiram controlar, de modo considerável, os números de homicídios em seus territórios. Destacamos em especial o caso de São Paulo, que logrou coibir um cenário de mais de 14 mil mortes violentas em 2002, reduzindo-as para pouco mais 4,5 mil em 2016 - um número ainda preocupante, porém significativamente menor que no início da série histórica.

Entre os fatores que podem explicar a queda no número absoluto de homicídios no estado de São Paulo no período considerado neste estudo, destacamos: a) a melhoria, ainda que aquém do que seria desejável, no padrão populacional de acesso à renda, ocupação e educação, que fez com que muitas pessoas tivessem a oportunidade de sair de uma conjuntura de vulnerabilidade ante às múltiplas formas de violência (PERES et al., 2011); b) a institucionalização do chamado regime disciplinar diferenciado (RDD), por intermédio da lei federal $n^{\circ} 10.792 / 2003$, que tornou mais severo e restritivo o cumprimento da pena por membros de organizações criminosas (BRASIL, 2003); e c) o envolvimento das comunidades nas políticas de segurança pública, de modo que as pessoas que residem nos territórios considerados mais violentos passaram a ser potenciais artífices na operacionalização de estratégias e/ou de políticas de combate ao crime (RUOTTI et al., 2017).

No Rio de Janeiro, boa parte da queda nos números de homicídios pode ser explicada pela criação do projeto das Unidades de Polícia Pacificadora (UPPs), que levaram policiamento às comunidades e áreas mais conflagradas, principalmente na capital. A nova política de segurança se deu muito em função do desejo de conter os indicadores de violência na cidade, que foi palco de megaeventos de proporções globais como a Copa do Mundo de 2014 e os Jogos Olímpicos de 2016, estes com sede na capital (CARDOSO et al., 2016). 
O comportamento de queda nos indicadores de homicídios nos estados de São Paulo e do Rio de Janeiro no período em análise não se repetiu no restante do país. Conforme se pontuou logo no começo deste tópico, de 2002 a 2016 houve uma ampliação de mais de 25\% no número de mortes violentas registradas em todo o território brasileiro.

Entre os fatores que de alguma forma explicam essa tendência de alta no número agregado de homicídios no Brasil, pontuam-se: a) a (re)organização das atividades de grupos criminosos no Brasil, que passaram a também atuar em territórios da região Norte, Nordeste e Centro-Oeste, provocando violência nessas localidades, sem que as forças de segurança dos estados tenham sido capazes de mapear e coibir esse movimento (FREITAS, 2018); b) a ampliação de conflitos por poder entre organizações criminosas, inclusive dentro do sistema penitenciário (BARROS et al., 2017); e c) a ampliação de formas particulares de homicídios, como aqueles motivados por conflitos agrários e ambientais (muito comuns no Norte e no Centro-Oeste), além de casos de feminicídio e transfeminicídio, que aumentaram em níveis consideráveis no período em análise (TAVARES et al., 2016).

Contemporaneamente, é possível observar no Brasil a ampliação do apoio popular a tendências significativamente autoritárias e ao uso da força por parte do aparato de segurança do Estado, o que certamente impacta os indicadores de violência (LIMA et al., 2020). De todo modo, merece destaque o fato de que os aspectos citados nos parágrafos anteriores desta seção representam, em nosso entender, explicações plausíveis, ainda que preliminares e incompletas, do comportamento dos indicadores de violência no Brasil registrados de 2003 a 2016.

No que tange à chegada de turistas internacionais ao Brasil, deve-se registrar que em 2016 o país recepcionou mais de 6,5 milhões de pessoas, a maioria vinda por transporte aéreo (pouco mais de 66\% do total), provenientes principalmente dos países da América do Sul e, em especial, da Argentina, país de origem de mais de 35\% dos turistas estrangeiros que chegaram ao Brasil em 2016 (MTUR, 2018).

São Paulo é o estado que mais recepcionou turistas estrangeiros em 2016, com um fluxo de mais de 2,2 milhões de pessoas, conforme pode-se observar no Gráfico 2. Logo na sequência aparecem Rio de Janeiro e Rio Grande do Sul, ambos com um montante de mais de 1,1 milhão de turistas no mesmo ano. Vale ponderar que São Paulo e Rio de Janeiro concentram os principais aeroportos internacionais do país, de modo que boa parte dos turistas provenientes da Europa, América Central, América do Norte, Ásia, Oceania e África desembarcam nesses estados, muito interessados no turismo corporativo e de eventos em São Paulo e no turismo de lazer e de "sol e praia" no Rio de Janeiro. Não obstante, o Rio Grande do Sul é também importante porta de entrada de turistas provenientes da América do Sul, sobretudo de argentinos, que se deslocam até o Brasil principalmente por vias terrestres e aquaviárias, muitos deles em direção às praias da região Sul, sobretudo as de Santa Catarina. 
Ao observar o Gráfico 2, percebe-se que o comportamento do fluxo de turistas estrangeiros no Rio de Janeiro ao longo da série histórica apresentou uma leve alta em 2014 e 2016, quando foram realizadas a Copa do Mundo e os Jogos Olímpicos, respectivamente.

Gráfico 2: Evolução da chegada de turistas estrangeiros nos principais estados que recepcionam esses visitantes

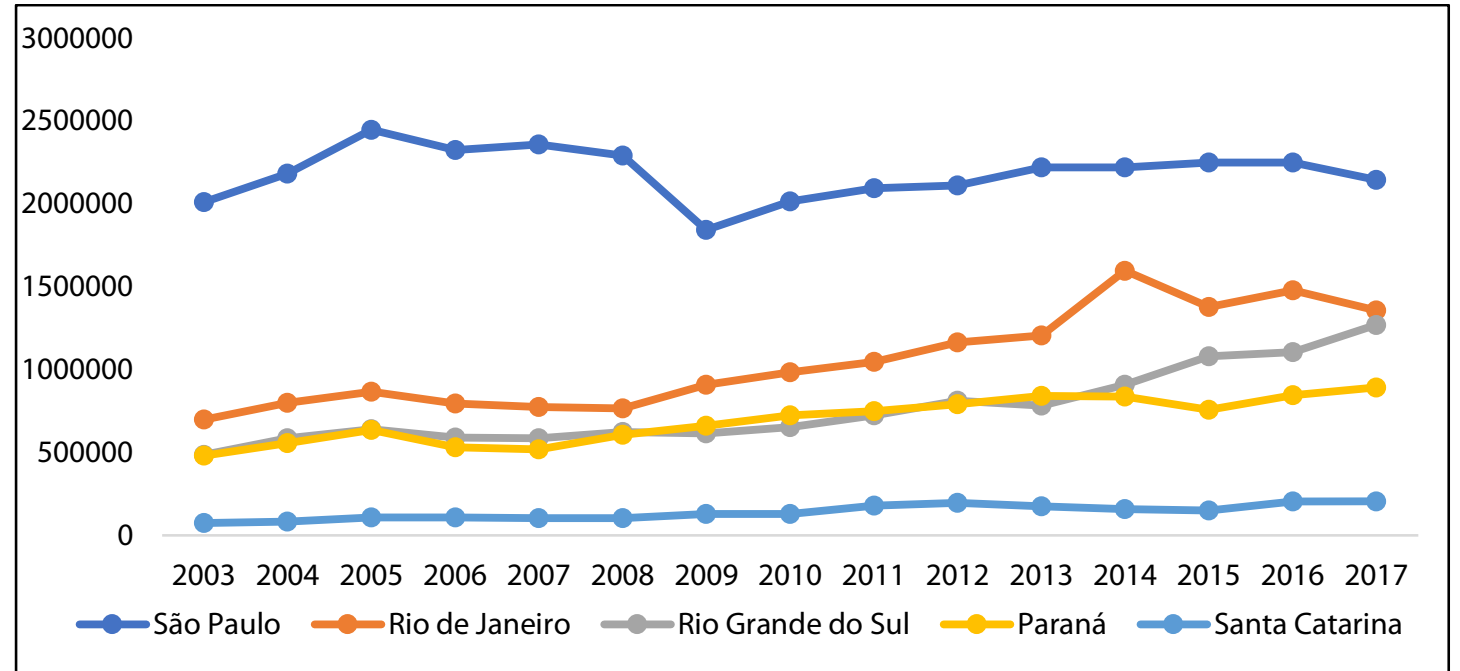

Fonte: Elaborado pelos autores, com base em MTUR (2018).

Rabahy (2019), ao refletir sobre a conjuntura do turismo receptivo de pessoas estrangeiras no Brasil, sugere que há um evidente quadro de estagnação nesse segmento, o que nos parece irônico, dado que o Brasil tem uma série de atrativos turísticos (re)conhecidos globalmente como as praias do Nordeste, Sudeste e Sul, a Amazônia e destinos de ecoturismo do Centro-Oeste.

Entre os fatores que explicam a conjuntura de estagnação do turismo receptivo internacional no Brasil, Rabahy (2019) também destaca: a) a falta de divulgação, fora do país, das múltiplas possibilidades de turismo no Brasil; b) a ausência de uma infraestrutura logística adequada, com fluxos regulares de voos para certos destinos turísticos e estradas que permitam o adequado e seguro deslocamento das pessoas; c) a carência de sujeitos fluentes em outras línguas (principalmente espanhol e inglês) e conscientes das especificidades socioculturais das múltiplas nacionalidades de turistas que eventualmente aportam no Brasil; e d) a falta de uma política pública que fomente as várias organizações envolvidas com o turismo internacional receptivo no Brasil.

Ao conduzirmos a primeira etapa do processo de análise dos dados estatísticos do artigo, nosso propósito foi, por intermédio de uma regressão linear simples, verificar se a chegada de visitantes estrangeiros em um determinado período (variável independente) impacta a quantidade absoluta de homicídios registrados no país no mesmo período - esta última entendida como a variável dependente do modelo. O Quadro 3 ilustra os resultados decorrentes da regressão linear em tela. 
Quadro 3: Influência da chegada de turistas nos números de homicídios do país

\begin{tabular}{cc}
\hline Regressão linear & $Y=1992,321+0,0024314$ (Turistas) \\
\hline Observações & 168 \\
\hline P-valor do modelo & 0 \\
\hline $\mathrm{R}^{2}$ ajustado & Intervalo de confiança (95\%) \\
\hline & {$[0,0020101 ; 0,0028527]$} \\
\hline Coef. angular & {$[1669,18 ; 2315,462]$} \\
\hline Coef. linear &
\end{tabular}

Fonte: Elaborado pelos autores.

Percebe-se que a regressão linear da primeira etapa se mostrou estatisticamente significativa, com um p-valor inferior a 0,05 (com um nível de significância de 95\%), e um $\mathrm{R}^{2}$ ajustado de $43,54 \%$. O resultado aponta que o modelo elaborado é capaz de prever, ainda que de forma limitada e parcial, quase a metade do comportamento apresentado pelos dados, ao serem analisados em conjunto. Vale frisar que, ao se observar a dispersão dos dados da amostra analisada, percebeu-se que o modelo linear "se ajusta" aos dados (a um nível de confiança de 95\%, com um p-valor menor que 0,05 ), corroborando a pertinência da técnica estatística usada nesta etapa do estudo e a pertinência da relação analisada, qual seja, a influência da chegada de turistas estrangeiros no número de homicídios no Brasil.

De maneira algébrica, a regressão da primeira etapa do estudo pode ser expressa por intermédio da seguinte equação:

$\mathrm{n}^{\circ}$ de homicídios $=1992,32+0,00243 .\left(\mathrm{n}^{\circ}\right.$ de turistas $)$

Em síntese, essa expressão algébrica indica que para cada novo turista estrangeiro a chegar ao Brasil, os homicídios potencialmente aumentam em 0,00243 unidades, ou seja, para cada mil visitantes, um total de 2,4 pessoas a mais, sejam residentes locais ou os próprios visitantes, tendem a ser acometidas por mortes violentas no país. Mesmo que o número de turistas estrangeiros não seja capaz de explicar, em sua completude, o comportamento do número de homicídios no país, é crucial ressaltar a existência de uma relação significativa, em termos estatísticos, entre as variáveis apresentadas.

Chama a atenção, nesta primeira etapa de análise dos dados estatísticos, o fato de que a chegada de turistas estrangeiros no Brasil impacta positivamente o número de homicídios registrados no país. De modo geral, tais resultados estão coerentes com as perspectivas de Devine (2017), Araña e León (2008), Bassil, Saleh e Anwar (2019), Coutinho, Nóbrega e Fazito (2020), e Grinols, Mustard e Staha (2011), citados ao longo de nossa discussão teórica. Tais autores sugerem que a presença de turistas estrangeiros é fonte de desordenamento dos territórios, em uma 
dinâmica que pode acirrar as múltiplas formas de violência, não raro contra os próprios visitantes provenientes de outros países.

Tomé (2013) pondera que os turistas, em geral, tomam decisões a partir da taxa de homicídios (não dos números absolutos), dado que a taxa, expressa em valores percentuais, é uma informação mais facilmente compreensível e comparável. Partindo dessa perspectiva, optamos por "construir" o valor da taxa de variação do número de homicídios de um dado período em relação aos valores do período imediatamente anterior. A expressão algébrica para o cálculo das taxas de variação do número de homicídios foi a seguinte:

$$
\operatorname{Variação}=\left(\frac{X_{t}}{X_{t-1}}\right)-1
$$

$X_{t}$ representa o número absoluto de homicídios em um determinado ano, ao passo que $X_{t-1}$ perfaz a mesma variável no período imediatamente anterior.

O Quadro 4 ilustra os principais coeficientes decorrentes da segunda etapa do estudo, calcada em um modelo de regressão linear simples. É oportuno salientar que os dados relativos à chegada de turistas estrangeiros no Brasil foram considerados em termos absolutos.

Quadro 4: Influência da taxa de variação dos homicídios sobre a chegada de turistas no país

\begin{tabular}{cc}
\hline Regressão linear & $\mathrm{Y}=542456-2037271$ (variação de homicídios) \\
\hline Observações & 168 \\
\hline P-valor do modelo & 0,1263 \\
\hline $\mathrm{R}^{2}$ ajustado & Intervalo de confiança $(95 \%)$ \\
\hline & {$[-2839631 ;-1234912]$} \\
\hline Coef. angular & {$[444379,2 ; 640532,9]$} \\
\hline Coef. linear &
\end{tabular}

Fonte: Elaborado pelos autores.

Percebe-se, com base nas informações do Quadro 4, que o modelo de regressão linear desta vez apresentou uma relação inversamente proporcional, indicando que, quando a taxa de homicídios sobe em um determinado ano, tem-se uma potencial queda na quantidade absoluta de turistas estrangeiros no país. De todo modo, o $\mathrm{R}^{2}$ ajustado foi de $12,63 \%$, revelando que, muito embora a taxa de homicídios seja uma variável que potencialmente impacta na chegada de turistas no Brasil, o poder explicativo de tal variável, tomada isoladamente, não é tão expressivo. Isso indica, notadamente, a necessidade de serem consideradas novas variáveis, em futuros estudos, que expliquem, de forma mais robusta em termos estatísticos, o comportamento do número de turistas estrangeiros no Brasil. 
Nessa etapa do estudo, verificou-se também a dispersão dos dados da amostra. Percebeu-se que o modelo linear se ajusta, de forma adequada, à distribuição dos dados, o que corrobora a pertinência do modelo de análise estatística escolhido. Entretanto, nesta etapa das análises, a capacidade de predição do número de turistas estrangeiros é de apenas 12,63\% quando se considera a taxa de variação de homicídios como variável independente das análises.

Assim, a expressão algébrica que sintetiza o modelo de regressão linear elaborado nesta etapa do estudo é a seguinte:

$\mathrm{n}^{\circ}$ de turistas=542456-2037,271 (\% de variação de homicídios)

Isso indica que para cada $1 \%$ de aumento nos casos levantados de mortes violentas, a quantidade de turistas estrangeiros que chegam ao Brasil é potencialmente reduzida em 2.037 pessoas, aproximadamente. Assim, vemos indícios de que a taxa de homicídios em um determinado ano pode potencialmente impactar - ainda que de forma limitada e com baixa capacidade de predição, conforme sinalizado anteriormente - a quantidade absoluta de turistas estrangeiros no ano imediatamente subsequente.

Motivados pela particularidade do segundo modelo, que considerou a taxa de variação de homicídios e sua respectiva influência na chegada de turistas, optamos por conduzir uma análise adicional no âmbito deste estudo, avaliando o impacto da quantidade de homicídios na variação do percentual de turistas que chegam ao Brasil. Em suma, percebeu-se que o modelo em questão não se mostrou significativo com um p-valor da variável independente em 0,553 - o que não é estatisticamente relevante, com um nível de significância de 95\%. Deve-se registrar que a análise, nesta avaliação em particular, foi feita com 167 elementos, em razão da falta de dados sobre a chegada de turistas ao Brasil anteriores a 2003.

Quadro 5: Influência do número absoluto de homicídios na chegada de turistas estrangeiros

\begin{tabular}{cc}
\hline Regressão linear & $Y=0,0373-0,000006$ ( $\mathrm{n}^{\circ}$ de homicídios) \\
\hline Observações & 167 \\
\hline P-valor do modelo & 0,553 \\
\hline $\mathrm{R}^{2}$ ajustado & $0,0 \%$ \\
\hline & Intervalo de confiança (95\%) \\
\hline Coef. angular & {$[-2,424 \mathrm{E}-05 ; 1,3031 \mathrm{E}-05]$} \\
\hline Coef. linear & {$[-0,0314 ; 0,1060]$} \\
\hline
\end{tabular}

Fonte: Elaborado pelos autores.

Portanto, a síntese das análises e reflexões deste texto sugerem a existência de interrelações entre os indicadores de homicídios e a chegada de turistas internacionais ao Brasil, com as 
seguintes particularidades: a) há fortes indícios de que a maior chegada de turistas estrangeiros resulte na ampliação dos números absolutos de homicídios no país - a relação entre as variáveis, aqui, é diretamente proporcional; e b) também há indícios, ainda que limitados e preliminares, de que eventuais aumentos na taxa de homicídios impliquem a diminuição do número de visitantes estrangeiros que chegam ao Brasil no ano subsequente - neste caso, a relação entre as variáveis é inversamente proporcional.

\section{Considerações finais}

Afinal, quais as características da relação, em termos estatísticos, entre os indicadores de homicídios e a chegada de turistas estrangeiros no Brasil?

Após as reflexões e análises estatísticas conduzidas, foi possível inferir as afirmações a seguir.

A presença de mais visitantes provenientes de outros países potencialmente provoca uma espécie de desordenamento nos territórios turísticos brasileiros que culmina em mais pessoas, tanto residentes locais como visitantes, acometidas por mortes violentas. De acordo com o modelo linear elaborado, para cada mil visitantes estrangeiros que o país recebe, há um total de 2,4 pessoas a mais vítimas de homicídio. Vale pontuar que o modelo linear elaborado para avaliar a influência da chegada de turistas estrangeiros nos indicadores de homicídios apresentou um coeficiente de determinação de 43,54\%, que, apesar de não explicar a completude do fenômeno estudado, confirma a existência de interrelações entre as variáveis estudadas.

No escopo da segunda etapa do estudo, percebeu-se que a taxa de variação de homicídios é uma variável que, apesar de possuir baixo poder de predição (apenas 12,63\%), influencia mesmo que de forma limitada e parcial, em termos estatísticos - a chegada de turistas estrangeiros ao Brasil. Assim, pode-se inferir que números muito altos nas taxas de homicídios em um determinado ano fazem com que, no ano subsequente, os turistas estrangeiros repensem seu desejo de visitar o Brasil. Conforme demonstrou-se ao longo do estudo, uma ampliação de $1 \%$ nas taxas de homicídio resulta na potencial desistência de 2.037 pessoas de outras nacionalidades de visitar o Brasil.

A pesquisa mostrou, mesmo que de modo não exaustivo, a realidade crônica de violência que acomete o Brasil, com números crescentes e alarmantes de homicídios. Além disso, o artigo revelou o caráter sistêmico e complexo do turismo receptivo internacional, que, além de potencialmente impactar o quadro de violência no país, também é potencialmente impactado pelos indicadores relativos aos números de homicídios que ocorrem em território brasileiro. 
Desse modo, entende-se, com base nos principais resultados e inferências deste artigo, que é urgente a elaboração de estratégias e políticas públicas que, por um lado, coíbam o quadro endêmico e preocupante de mortes violentas no país - até como forma de atrair mais visitantes - e, por outro, também consigam ordenar os impactos da presença de um maior quantitativo de turistas estrangeiros nos territórios turísticos. $\mathrm{Na}$ ausência de ordenamento, corre-se o risco de que a própria presença de visitantes de outros países possa provocar uma ampliação dos indicadores de homicídios.

Um último aspecto que merece ser realçado é o fato de que o caráter sistêmico e complexo do turismo faz com que as estratégias e políticas públicas de fomento à atividade turística tenham que ser igualmente sistêmicas e complexas. O combate às múltiplas formas de violência, além do ordenamento dos impactos da presença de visitantes nos territórios, deve, sim, compor o quadro de preocupações dos gestores no planejamento dessa importante atividade socioeconômica.

É notório que o presente estudo não pretendeu, em momento algum, ser exaustivo e completo. A própria escolha dos modelos estatísticos empregados revela uma limitação. De todo modo, as reflexões sugerem a necessidade de novos estudos sobre as interconexões entre turismo e violência, tendo como escopo a título de sugestão: a) a compreensão, a partir de um viés epistemológico qualitativo, da dinâmica dos múltiplos impactos que a presença de visitantes estrangeiros proporciona nos territórios turísticos; b) a análise dos caminhos para a (re)formulação, implementação e avaliação de políticas públicas que estimulem o turismo receptivo internacional, sem que tal atividade gere violência nos territórios turísticos; e c) as formas a partir das quais a violência manifesta-se contra os visitantes estrangeiros nos destinos turísticos nacionais. 


\section{Referências}

AMORIN, Ericka; GANDARA, Jose Manoel; TARLOW, Peter; KORSTANJE, Maximiliano. "Seguridad percibida en la ciudad de Curitiba: Un sondeo exploratorio en residentes locales y turistas”. Revista de Análisis Turístico, vol. 12, n. 14, pp. 1-9, 2012.

ARAÑA, Jorge; LEÓN, Carmelo. "The Impact of Terrorism on Tourism Demand”. Annals of Tourism Research, vol. 35, n. 2, pp. 299-315, 2008.

ARRUDA, Dyego de Oliveira; MARIANI, Milton; CALEMAN, Silvia. “Coordinación y estructuras de gobernanza en un sistema productivo de turismo". Estudios y Perspectivas en Turismo, vol. 23, n. 2, pp. 343-361, 2014.

BARROS, João Paulo; BENICIO, Luis Fernando de Souza; BARBOZA DA SILVA, Dagualberto; LEONARDO, Camila dos Santos; TORRES, Frida Jaina Popp. "Homicídios juvenis e os desafios à democracia brasileira: Implicações ético-políticas da psicologia". Psicologia: Ciência e Profissão, vol. 37, n. 4, pp. 1051-1065, 2017.

BASSIL, Charbel; SALEH, Ali Salman; ANWAR, Sajid. "Terrorism and Tourism Demand: A Case Study of Lebanon, Turkey and Israel”. Current Issues in Tourism, vol. 22, n. 1, pp. 50-70, 2019.

BOAVIDA-PORTUGAL, Inês; FERREIRA, Carlos Cardoso; ROCHA, Jorge. "Where to vacation? An Agent-Based Approach to Modelling Tourist Decision-Making Process". Current Issues in Tourism, vol. 20, n. 15, pp. 1557-1574, 2017.

BRASIL. Lei no 10.792, de 1 de dezembro de 2003. Brasília, DF: Presidência da República, 2003. Disponível em: http://www.planalto.gov.br/ccivil_03/leis/2003/110.792.htm

BÜSCHER, Bram; FLETCHER, Robert. "Destructive Creation: Capital Accumulation and the Structural Violence of Tourism". Journal of Sustainable Tourism, vol. 25, n. 5, pp. 651-667, 2017.

CARDOSO, Francisca; CECCHETTO, Fátima Regina; CORRÊA, Juliana Silva; OLIVEIRA DE SOUZA, Tiago. "Homicídios no Rio de Janeiro, Brasil: Uma análise da violência letal". Ciência \& Saúde Coletiva, vol. 21, n. 4, pp. 1277-1288, 2016.

COSTA, Jean; BRANDÃO, Thadeu de Sousa; HERMES JUNIOR, Ivenio do Espírito Santo; PINTO DE FARIAS, Tássio Ricelly. “Polícia do turista': Contradições e revelações”. International Journal of Safety and Security in Tourism/Hospitality, n. 18, pp. 1-12, 2018.

COUTINHO, Ana Catarina Alves; NÓBREGA, Wilker Ricardo; FAZITO, Mozart. "Turismo e medo do crime: Reflexões sobre a política de desenvolvimento urbano no centro histórico de Natal/RN”. Novos Cadernos Naea, vol. 23, n. 3, pp. 81-104, 2020.

CRESWELL, John W. Projeto de pesquisa: Métodos qualitativo, quantitativo e misto. Porto Alegre: Artmed, 2010.

DEVINE, Jennifer. “Colonizing Space and Commodifying Place: Tourism’s Violent Geographies”. Journal of Sustainable Tourism, vol. 25, n. 5, pp. 634-650, 2017.

FBSP. Atlas da violência 2018. Fórum Brasileiro de Segurança Pública (FBSP). Rio de Janeiro: Ipea/FBSP, 2018. 
FBSP. Atlas da violência 2020. Fórum Brasileiro de Segurança Pública (FBSP). Rio de Janeiro: Ipea/FBSP, 2020.

FERREIRA, Sanette; HARMSE, Alet. "Crime and Tourism in South Africa: International Tourists' Perception and Risk". South African Geographical Journal, vol. 82, n. 2, pp. 80-85, 2000.

FOURIE, Johan; ROSSELLÓ-NADAL, Jaume; SANTANA-GALLEGO, María. "Fatal Attraction: How Security Threats Hurt Tourism”. Journal of Travel Research, vol. 59, n. 2, pp. 209-219, 2020.

FREITAS, Melina Wedoy. Tendência da mortalidade por homicídios no Brasil: 1996-2016. Dissertação (Mestrado em Saúde Coletiva) - Universidade do Vale do Rio dos Sinos, São Leopoldo, 2018.

FREITAS, Ricardo; GOTARDO, Ana Teresa. "Marcas do Rio pré-olímpico: Imaginários de sexo, violência e epidemias em um canal sino-americano do YouTube". Caderno Virtual de Turismo, vol. 18, n. 1, pp. 40-52, 2018.

GLENSOR, Ronald; PEAK, Kenneth. Crimes Against Tourists. Washington, D.C.: U.S. Department of Justice, 2004.

GRINOLS, Earl; MUSTARD, David; STAHA, Melissa. "How Do Visitors Affect Crime?". Journal of Quantitative Criminology, vol. 27, n. 3, pp. 363-378, 2011.

HAIR, Joseph et al. Análise multivariada de dados. Porto Alegre, RS: Bookman, 2009.

LIMA, Renato; JANNUZZI, Paulo de Martino; MOURA JUNIOR, James F.; SEGUNDO, Damião S. de Almeida."Medo da violência e adesão ao autoritarismo no Brasil: Proposta metodológica e resultados em 2017”. Opinião Pública, vol. 26, n. 1, pp. 34-65, 2020.

LÓPEZ, Edith. “Turismo y miedo al delito-violencia: El caso de la ciudad histórica de Guanajuato (México)". Estudios y Perspectivas en Turismo, vol. 27, pp. 805-830, 2018.

MTUR. Anuário estatístico do turismo - 2018. Ministério do Turismo (MTUR). Brasília, DF: MTUR, 2018.

NEUMAYER, Eric. "The Impact of Political Violence on Tourism: Dynamic Cross-National Estimation”. Journal of Conflict Resolution, vol. 48, n. 2, pp. 259-281, 2004.

PERES, Maria et al. "Queda dos homicídios no município de São Paulo: Uma análise exploratória de possíveis condicionantes”. Revista Brasileira de Epidemiologia, vol. 14, n. 4, pp. 709-721, 2011.

PISCITELLI, Adriana. “\#queroviajarsozinhasemmedo': Novos registros das articulações entre gênero, sexualidade e violência no Brasil”. Cadernos Pagu, n. 50, pp. 1-37, 2017.

PIZAM, Abraham. "A Comprehensive Approach to Classifying Acts of Crime and Violence at Tourism Destinations”. Journal of Travel Research, vol. 38, n. 1, pp. 5-12, 1999.

PIZAM, Abraham; TARLOW, Peter; BLOOM, Jonathan. "Making Tourists Feel Safe: Whose Responsibility Is It?”. Journal of Travel Research, vol. 36, n. 1, pp. 23-28, 1997.

PRODANOV, Cleber; FREITAS, Ernani. Metodologia do trabalho científico: Métodos e técnicas da pesquisa e do trabalho acadêmico. Novo Hamburgo, RS: Feevale, 2013.

RABAHY, Wilson Abrahão. "Análise e perspectivas do turismo no Brasil". Revista Brasileira de Pesquisa em Turismo, vol. 14, n. 1, pp. 1-13, 2019. 
RUOTTI, Caren; REGINA, Fernanda Lopes; ALMEIDA, Juliana Feliciano de; NASSER, Marina Mattar Soukef. “A ocorrência de homicídios no município de São Paulo: Mutações e tensões a partir das narrativas de moradores e profissionais”. Saúde e Sociedade, vol. 26, n. 4, pp. 999-1014, 2017.

SEDERATI, Pooyan; SANTOS, Sérgio; PINTASSILGO, Pedro. "System Dynamics in Tourism Planning and Development”. Tourism Planning \& Development, vol. 16, n. 3, pp. 256-280, 2019.

SILVA, Sergio. "Preconceito e discriminação: As bases da violência contra a mulher". Psicologia: Ciência e Profissão, vol. 30, n. 3, pp. 556-571, 2010.

TAVARES, Ricardo; CATALAN, Valeria Dutra Batista; ROMANO, Pedro Machado de Melo; MELO, Elza Machado. "Homicídios e vulnerabilidade social". Ciência \& Saúde Coletiva, vol. 21, n. 3, pp. 923-934, 2016.

TOMÉ, Marcello. “Turismo, medo e violência”. Turismo \& Sociedade, vol. 6, n. 1, pp. 225-228, 2013.

TOMÉ, Marcello. “Turismo e medo social: Análise da segurança pública durante a Copa do Mundo FIFA 2014, na cidade do Rio de Janeiro-RJ, Brasil”. Revista Turismo \& Desenvolvimento, vol. 2, n. 27-28, pp. 13-16, 2017.

WTTC. Travel \& Tourism Global Economic Impact \& Trends 2020. World Travel \& Tourism Council (WTTC). Londres: WTTC, 2020a.

WTTC. Brazil - 2020 Annual Research: Key Highlights. World Travel \& Tourism Council (WTTC). Londres: WTTC, 2020b.

ARTHUR CALDEIRA SANCHES (arthur.sanches@ufms.br) é professor efetivo da Universidade Federal de Mato Grosso do Sul (UFMS, Campo Grande, Brasil). É doutor e mestre pelo Programa de Pós-Graduação em Administração (PPGAD) da UFMS e tem graduação em administração pela mesma universidade.

https://orcid.org/0000-0003-0859-5574

DYEGO DE OLIVEIRA ARRUDA (dyego.arruda@gmail.com) é professor efetivo do Centro Federal de Educação Tecnológica Celso Suckow da Fonseca (Cefet/RJ, Valença, Brasil) e leciona no Programa de Mestrado em Relações Étnico-Raciais (PPRER) e em cursos de graduação da instituição. É doutor pelo Programa de Pós-Graduação em Administração de Organizações (PPGAO) da Universidade de São Paulo (USP, Ribeirão Preto, Brasil), mestre pelo PPGAD da UFMS e graduado em ciências econômicas pela mesma universidade.

https://orcid.org/0000-0002-9514-284X 
MILTON AUGUSTO PASQUOTTO MARIANI

(miltmari@terra.com.br) é professor efetivo da UFMS e leciona no PPGAD e no Programa de PósGraduação em Estudos Fronteiriços (PPGEF) da mesma universidade. É doutor pelo Programa de Pós-Graduação em Geografia Humana (PPGH) da USP, mestre pelo Programa de Pós-Graduação em História da Pontifícia Universidade Católica de São Paulo (PUC-SP, São Paulo, Brasil) e graduado em geografia pela Universidade Estadual Paulista Júlio de Mesquita Filho (Unesp, Presidente Prudente, Brasil).

https://orcid.org/0000-0001-9485-0150

\section{Colaboradores}

ACS trabalhou na concepção, no delineamento, na análise e na interpretação dos dados do artigo. DOA trabalhou na concepção e na redação final do manuscrito. MAPM atuou na concepção, na revisão crítica do manuscrito e na aprovação da versão final.

Recebido em: 23/03/2020 Aprovado em: 07/06/2021 